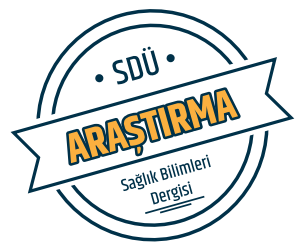

Sdü Sağlık Bilimleri Dergisi / Cilt 10 Sayı 1 / 2019

\title{
ST Segment Yükselmeli Miyokart Enfarktüslü Hastalarda Aortik Sertliğin Primer Perkütan Koroner Girişim Sonrasında Elektrokardiyografik Reperfüzyon Üzerine Etkisi
}

Effect of Aortic Stiffness on Electrocardiographic Reperfusion
in Patients with ST-Elevation Myocardial Infarction (STEMI)
Who Underwent Primary Percutaneous Coronary Intervention

\begin{abstract}
İsmail Barkın Işık ${ }^{1}$ Ahmet Altınbaş², Fatih Kahraman ${ }^{3}$, Fatih Aksoy², Ali Bağcı ${ }^{4}$, Yunus Emre Okudan ${ }^{5}$
${ }^{1}$ Rize Devlet Hastanesi, Rize, Türkiye.

${ }^{2}$ Süleyman Demirel Üniversitesi Araştırma ve Uygulama Hastanesi, Isparta, Türkiye.

${ }^{3}$ Kütahya Sağlık Bilimleri Üniversitesi Evliya Çelebi Eğitim ve Araştırma Hastanesi, Kütahya, Türkiye.

${ }^{4}$ Isparta Şehir Hastanesi, Isparta, Türkiye.

5İzmit Seka Devlet Hastanesi, İzmit, Türkiye.
\end{abstract}

\section{Özet}

Amaç: Aortik sertlik iyi bilinen bir vasküler yaşlanma göstergesidir ve koroner ateroskleroz ile ilişkisi de bilinmektedir. Ancak aortik sertliğin miyokart enfarktüsü sonrası sol ventrikül fonksiyonları üzerine etkisi hakkında elimizde yeterli bilgi yoktur. Çalışmamızda aortik sertliğin, ST eleve miyokart enfarktüsünde (STEMI) primer perkütan koroner girişim (PKG) sonrası elektrokardiyografik reperfüzyon ve enfarkt genişliği üzerine etkisini incelemeyi planladık.

Materyal-Metot: STEMI tanısıyla PKG yapılan 253 hastanın başlangıçta ve işlemden hemen sonra çekilen EKG'lerinde total ST rezolüsyonuna bakılmıştır. Hastaların işlem sonrası 48-72. saatlerinde ekokardiyografileri yapılmış ve aortik çaplar ile arteriyel tansiyon ölçümleri kullanılarak aortik sertlik parametreleri elde edilmiştir. Ejeksiyon fraksiyon (EF) değerleri biplane modifiye simpson metodu ile ortalama alınarak saptanmıştır. Enfarkt alanı göstergesi olarak pik CKMB değerleri kullanılmıştır.

Bulgular: Çalışmamızda PKG sonrası elektrokardiyografik olarak başarılı reperfüzyon saptanan hastalarda aortik sertlik daha düşük (aortik strain için 14,5 $\pm 3,7$ vs 7,8 $\pm 1,8$ p=0,0001; aortik distensibilite için $7,4 \pm 3,0$ vs $2,5 \pm 0,8 \mathrm{p}=0,0001$; aortik sertlik indeksi için $3,1 \pm 0,9$ vs $7,2 \pm 2,4 \mathrm{p}=0,0001$; aortik elastik modülüs için $303 \pm 105$ vs $863 \pm 321 \mathrm{p}=0,0001)$ ve pik CK-MB değerleri daha düşük saptanmıştır $(103,1 \pm 15,5 \mathrm{mg} / \mathrm{dl}$ vs $121,2 \pm 22,4 \mathrm{mg} / \mathrm{dl}$ $\mathrm{p}<0,001)$. Ayrıca sol ventrikül ejeksiyon fraksiyonu da (SVEF) düşük aortik sertlikle ilişkili saptanmıştır $(\mathrm{p}=0,001)$.

Sonuç: Çalışmamızda, PKG uygulanan STEMİ hastalarında artmış aortik sertliğin, daha kötü elektrokardiyografik reperfüzyon ve daha büyük enfarkt alanları ile ilişkili olduğu belirlendi. Bu durum miyokart enfarktüsü sonrası yeniden yapılanma gelişiminde bir role sahip olabilir.

Anahtar kelimeler: Koroner Arter Hastalığı, Aortik Sertlik, Miyokart Enfarktüsü, Koroner Reperfüzyon, Elektrokardiyografi.

\begin{abstract}
Objective: Aortic stiffness is a well-known indicator of vascular aging and the relationship with atherosclerosis is well defined. However the effect of aortic stiffness on left ventricle after myocardial infarction is not so clear. In the present study we studied the effect of aortic stiffness on infarct area and electrocardiographic reperfusion in patients with ST-elevation myocardial infarction (STEMI) who underwent primary percutaneous coronary intervention (PCI).
\end{abstract}

Material-Method: Total ST resolution was examined on the electrocardiograms (ECG) of 253 patients who underwent PCI for the diagnosis of STEMI, taken right after the procedure. Echocardiographic measurements were performed at 48-72 hours after the procedure and aortic stiffness parameters were obtained using the measurements of aortic diameter and arterial pressure. Ejection fraction $(\mathrm{EF})$ was detected by taking the average with the biplane modified simpson method. Peak creatine kinase MB (CK$\mathrm{MB}$ ) isoenzyme levels were used as the indicator of infarct area.

Results: Our study showed that in patients that have shown electrocardiographic successful reperfusion, have better aortic stiffness values (aortic strain $14,5 \pm 3,7$ vs $7,8 \pm 1,8 \mathrm{p}=0,0001$; distensibility $7,4 \pm 3,0$ vs $2,5 \pm 0,8 \mathrm{p}=0,0001$; aortic stiffness index $3,1 \pm 0,9$ vs $7,2 \pm 2,4 \mathrm{p}=0,0001$; aortic eleatic modül $303 \pm 105$ vs $863 \pm 321 \mathrm{p}=0,0001)$ and smaller peak CK-MB levels $(103,1 \pm 15,5 \mathrm{mg} / \mathrm{dl}$ vs $121,2 \pm 22,4 \mathrm{mg} / \mathrm{dl} \mathrm{p}<0,001)$ Additionally another correlation was showing that left ventricular EF(LVEF) was better in patients with higher aortic strain levels $(\mathrm{p}=0.001)$.

Conclusions: The present study suggested that higher aortic stiffness in patients with STEMI undergone PCI is associated with worse electrocardiographic reperfusion and larger infarct area. This situation can have a role on reverse remodeling development after myocardial infarction.

Keywords: Coronary Artery Disease, Aortic Stiffness, Myocardial Infarction, Coranary Reperfusion, Electrocardiography. 


\section{Giriş}

Koroner arter hastalığı (KAH) günümüzde halen gelişmiş ve gelişmekte olan ülkelerde olduğu gibi ülkemizde de morbidite ve mortalitenin en önemli nedenlerindendir (1). Koroner arter hastalı̆̆ının alt grubu olan akut koroner sendromlar (AKS); kararsız anjina pektoris (USAP), ST segment yükselmeli miyokard infarktüsü (STEMI), non-ST segment yükselmeli miyokard infarktüsü (NSTEMI) ve ani kardiyak ölüm olmak üzere geniş spektrumlu bir dizi klinik tabloyu içermektedirler. Anatomik olarak ise normale yakın, tek damar ya da çok damar hastalığ 1 şeklinde görülmektedir (2). ST yükselmesiz MI‘da sorumlu lezyon, sıklıkla yırtılmış veya erozyona uğramış plak içinde trombositten zengin, beyaz trombüstür, kısmen veya aralıklı tıkayıcıdır. Tam okluzif trombüs etkilenen koroner arter tarafindan beslenen miyokart duvarında enfarkta neden olur ve ST segment yükselmeli MI (STEMI) gelişir (3). Koroner arter hastalarında arteriyel sertlik gelişiminin kardiyovasküler olay ve MI gelişimi ile olan ilişkisi yapılan çalışmalarda gözlenmiştir (4).

Aortik sertlik aort duvarının mekaniksel gerilimini ve elastikiyetini yansitır (5). Yapılan calışmalarda, hipertansiyon, diabetes mellitus (DM), ateroskleroz, kronik böbrek yetersizliği, bağ doku hastalıkları, sigara içme ve yaşlanma ile birlikte aort sertliğinin arttığı gösterilmiştir (6). Aort elastisitesi kardiyovasküler mortalite ile yakından ilişkilidir. $\mathrm{KAH}$ varlığında, aort sertliğinin arttığı ve aort sertliğinin KAH'nı öngördügü̈ bilinmektedir (7). Günümüzde aortik sertlik gelişecek kardiyovasküler olaylar için bağımsız bir prediktör olarak kabul edilmektedir (8). Tüm bunlar aortik sertliğin koroner arter hastalığının her aşamasıyla kuvvetli bağları olan, aralarında sebep sonuç ilişkileri bulunan önemli bir klinik durum olduğunu bizlere göstermektedir (9). Özellikle yaşla artan aortik sertlik durumunun miyokart enfarktüsü sonrası daha geniş enfarkt alanları, daha kötü sol ventrikül fonksiyonları ile birlikte olduğu bilinse de aortik sertliğin miyokart enfarktüsü sonrası yeniden yapılanma üzerine etkisi hakkında elimizde yeterli bilgi yoktur (1011). Bu çalışmamızda biz de aortik sertliğin, ST eleve miyokart enfarktüsünde (STEMI) primer PKG sonras1 elektrokardiyografik ST rezolüsyonu ve enfarkt genişliği üzerine etkisini incelemeyi planladık.

\section{Materyal-Metot}

Çalışmaya, Nisan 2016-Ocak 2017 tarihleri arasında Süleyman Demirel Üniversitesi Araştırma ve Uygulama Hastanesi acil servisine göğüs ağrısı şikayeti ile başvuran, acil serviste akut ST elevasyonlu MI tanısı konup; primer perkütan koroner girişim işlemi hakkında bilgi verilen ve ağrısının ilk 12. saatinde olup trombolitik tedavi verilmeyen ve başarılı primer perkütan koroner girişim uygulanan toplam 253 hasta dahil edildi. Çalışmaya dahil edilen tüm hastalardan yazilı onam belgeleri alındı.

Çalışmaya dahil edilen tüm hastaların işlem öncesi ve işlemden hemen sonraki EKG'leri çekildi. Başarılı perkütan koroner girişim sonrası Thrombolysis In Myocardial Infarction (TIMI) III akım elde edilen hastaların EKG'deki total ST segment rezolüsyonu değerlendirildi. Tüm derivasyonlardaki
ST segment yüksekliğinin toplamı belirlendi ve $\geq \% 70 \mathrm{ST}$ segment rezolüsyonu olması başarılı elektrokardiyografik reperfüzyon kriteri olarak kabul edildi. Hastalar ST segment rezolüsyonu olan ve olmayan olmak üzere iki gruba ayrıldı.

Çalışmaya dahil edilen tüm hastaların anamnez bilgileri, kardiyak risk faktörleri, vital bulguları kaydedildi. Hastaların koroner yoğun bakıma yatış anında hemogram ve biyokimyasal parametreleri alındı. Hastalardan enfarkt genişliğinin belirteci olarak CK-MB değeri 4 saatlik aralıklarla ilk başvuru anından itibaren ta $\neg$ kip edildi ve pik CK-MB değeri saptandı. Hastaların transtorasik ekokardiyografileri, PKG sonrası 48-72. saatleri arasında yapıldı. Rutin ekokardiyografik değerleri ve aortik sertlik parametreleri hesaplandi. Hastaların ekokardiyografi öncesinde ve sonrasında sistolik (SKB) ve diyastolik (DKB) kan basınçları 2 kez sfingomanometrik yöntemle dominant olmayan koldan ölçülüp ortalamaları alındı.

\section{Çalışmaya Dahil Edilmeme Kriterleri}

Yapısal kalp hastalığı olanlar, başarısız PKG hastaları, ilk 12 saatin dişında başvuran hastalar, perikardiyal effüzyonu olanlar, transtorasik ekokardiyografide yetersiz görüntü kalitesi olanlar, kalp yetmezliği $(\mathrm{EF}<\% 50)$ öyküsü olanlar, kronik böbrek hastalığ derecede mitral ve aort kapak darlığı/yetmezliği olanlar, kronik karaciğer hastalığı olanlar, malignitesi olanlar, sistemik / pulmoner emboli öyküsü olanlar, prostetik kapağ olanlar, akut / kronik inflamatuar hastalığı olanlar, kronik hematolojik hastalığı olanlar çalışma dışı bırakıldı.

\section{Klinik Değerlendirme}

Olgulara ait anamnez bilgileri, yaş, cinsiyet, hipertansiyon (antihipertansif ilaçlar ile tedavi edilen, bilinen hipertansiyon veya iki kez kan basıncı ölçümünün 139/89 mmHg üzerinde olması), tütün kullanımı (halen sigara içimi ya da son on iki ay içinde sigara içilmesi), diyabetes mellitus (AKŞ düzeyinin $126 \mathrm{mg} / \mathrm{dl}$ ve/veya $126 \mathrm{mg} / \mathrm{dl}$ üzerinde olmas1 veya DM nedeniyle tedavi alıyor olması), hiperkolesterolemi (herhangibir zamanda TK değerinin bir kez 200 mg/dl üzerinde ya da hastanın HL tedavisi açısından tedavi alıyor olması) aile öyküsü (birinci derece akrabalardan erkekte 55, kadında 65 yaşından önce koroner arter hastalığı veya ani kardiyak ölüm öyküsü olması) ve KAH (angiografik olarak $\% 50$ ya da daha fazla koroner lezyon varlı̆g ya da daha önce koroner by-pass ya da perkutan koroner girişim öyküsü olması) bilgileri kaydedildi.

\section{Biyokimyasal Parametrlerin Elde Edilmesi}

Olguların tam kan sayımı, biyokimyasal ve hormonal parametreleri Süleyman Demirel Üniversitesi Tıp Fakültesi Merkez Biyokimya Laboratuvarı bünyesinde bulunan Bechman Coulter LH 780 cihazıyla çalışılırken, biyokimyasal ölçümler ise Bechman Coulter Oluympus A4 5800 cihazıyla çalışıldı.

\section{Ekokardiyografik İnceleme}

Tum hastaların M-mod ve 2-D imajlar ve spektral ve renkli akım dopler kayıtları, değişik frekansda duzenlenen (2,5-3,5 $\mathrm{MHz}$ ) transduserle GE Vingmed Vivid 7 ekokardiyografi 
cihazı kullanılarak alındı. Rutin ekokardiyografi incelemesi sonrası hastalar hafif sırtüstü yatar pozisyona getirilip 2-D kılavuzluğunda M Mod ile asendan aort kayıtları alındı. $\mathrm{Bu} \mathrm{M}$ mod asendan aorta kayıtları aort kapağın $3 \mathrm{~cm}$ kadar uzerinden yapıldı. Aort capları sistolde ve diyastolde aortun ön ve arka duvar iç kenarları arasındaki mesafeler alınarak hesaplandı (Şekil-1). Aortun sistolik çapı (AoS), aort kapağ 1 tam açık konumda iken alındı. Aortun diyastolik çapı ise (AoD) EKG kayıtlarında QRS'in tepe noktası ile eş zamanlı alındı. Arka arkaya 5 atımda ölçüm yapıldı ve ortalamaları alındı. Bu parametrelere ek olarak, tüm hastalarda sol ventrikül ejeksiyon fraksiyonu (EF), sol ventrikül sistol sonu çap1, sol ventrikül diyastol sonu çap1, sol ventrikül posterior duvar kalınlığı ve interventriküler septum kalınlığı gibi ekokardiyografik parametreler ölçüldü.

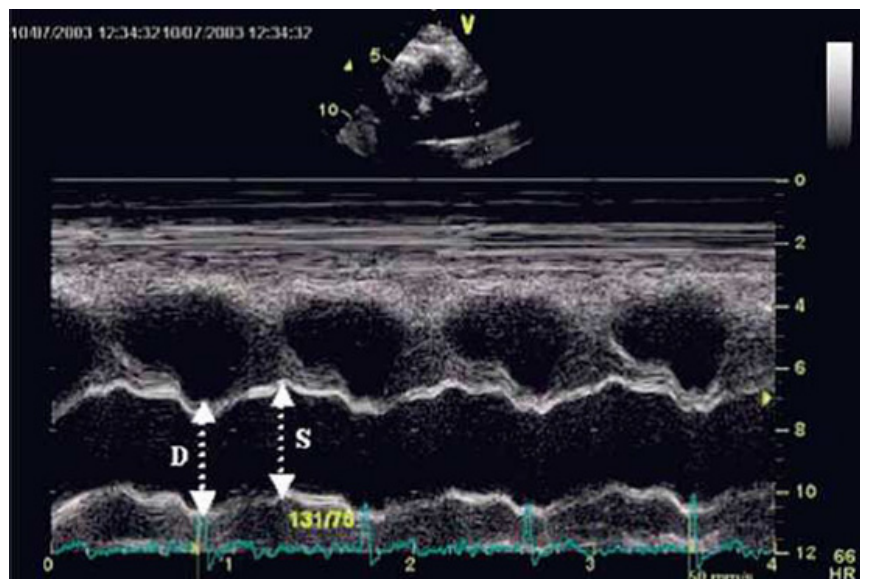

Şekil 1. Aortun sistol ve diastol sırasında çaplarının ölçümü

\section{Aortik Sertlik Parametrelerinin Hesaplanması}

Aort elastik parametreleri aort fonksiyonunun göstergeleri olarak kabul edildi. Her hasta icin aort sistolik (AoS) ve diyastolik (AoD) indeksleri sistolik ve diyastolik aort çaplarının vücüt kitle indeksine bölümü ile elde edildi. $\mathrm{Bu}$ indeksler kullanılarak aortun elastik özellikleri olarak aşağıdaki parametreler hesaplandı.

-Aortik Strain

Aortik strain $(\%)=($ sistolik aortik çap - diyastolik aortik çap $)$ X 100 / diyastolik aortik çap

-Aortik Distensibilite (Kompliyans)

Distensibilite $\left(\mathrm{cm}^{2} /\right.$ dyn $\left./ 10^{3}\right)=(2 \mathrm{X}$ aortik strain $) /($ sistolik kan basınc1-diyastolik kan basinc1)

-Aortik Sertlik İndeksi (Beta) (ASİ)

ASI: In (Sistolik Kan basıncı / Diyastolik Kan basınc1) / Aortik strain

-Aortik Elastik Modülüs (E(p))

E(p):Nabız Basınc1 / Aortik strain

-Nabiz basincı (mmHg)

Sistolik kan basınc1-Diyastolik kan basıncı

\section{İstatistiksel Analiz}

Çalışmada elde edilen bulgular değerlendirilirken, istatiksel analizler için SPSS (Statiscal Package for Social Sciences) for window 22.0 programı kullanıldı. Sürekli değişkenler ortalama \pm standart sapma, kesikli değişkenler ise sayı ya da yüzde (\%) olarak verildi. Gruplar arası (ST segment rezolusyonu olan ve olmayan) bağımsız değişkenlerin (Aortik sertlik parametreleri vs.) karşılaştırılmasında Chi-square ve Student T testleri kullanıldı. ST segment rezolusyonu varlığı, aortik sertlik parametreleri ve diğer klinik, ekokardiyografik ve laboratuvar parametreler arasındaki korelasyon, pearson ve spearman korelasyon analizleri ile değerlendirildi. P değerinin 0,05 'den düşük saptanması istatistiksel olarak anlamlı kabul edildi.

\section{Bulgular}

Çalışmaya alınan hastaların demografik ve fizik muayene özelliklerinin karşılaştırılması Tablo 1'de özetlenmiştir.

Tablo 1. ST rezolusyonu olan ve olmayan hastaların demografik ve fizik muayene özelliklerinin karşılaştırılması

\begin{tabular}{lccc}
\hline & $\begin{array}{c}\text { ST Rez. } \\
\text { Var } \\
\text { (n:122) }\end{array}$ & $\begin{array}{c}\text { ST Rez. } \\
\text { Yok } \\
\text { (n:131) }\end{array}$ & P Değeri \\
\hline Yaş (yıl) & $57,9 \pm 10,7$ & $66,5 \pm 10,8$ & $\mathbf{0 , 0 0 1 *}$ \\
\hline Cinsiyet (E / K) & $73 / 49$ & $64 / 67$ & 0,235 \\
\hline $\begin{array}{l}\text { Tanı (Ant. MI / Non- } \\
\text { Ant. MI) }\end{array}$ & $71 / 51$ & $55 / 76$ & $\mathbf{0 , 0 4 3 *}$ \\
\hline KAH, n(\%) & $12(9,8)$ & $81(61,8)$ & $\mathbf{0 , 0 0 1 *}$ \\
\hline Sigara, n(\%) & $48(39,3)$ & $56(42,7)$ & 0,582 \\
\hline Heredite, n(\%) & $22(18)$ & $10(7,6)$ & 0,134 \\
\hline DM, n(\%) & $25(20,5)$ & $58(44,3)$ & $\mathbf{0 , 0 0 1 *}$ \\
\hline HT, n(\%) & $18(14,8)$ & $110(84)$ & $\mathbf{0 , 0 0 1 *}$ \\
\hline HL, n(\%) & $17(13,9)$ & $53(40,5)$ & $\mathbf{0 , 0 0 1 *}$ \\
\hline Obezite, n(\%) & $16(13,1)$ & $28(21,4)$ & 0,082 \\
\hline SKB (mm/Hg) & $119,3 \pm 13,5$ & $151,4 \pm 13,1$ & $\mathbf{0 , 0 0 1 *}$ \\
\hline DKB (mm/Hg) & $78,1 \pm 10,6$ & $88,4 \pm 8,6$ & $\mathbf{0 , 0 0 1 *}$ \\
\hline NB (mm/Hg) & $41 \pm 7,1$ & $62,9 \pm 6,7$ & $\mathbf{0 , 0 0 1 *}$ \\
\hline PKG(LAD/RCA/Cx) & $70 / 33 / 19$ & $55 / 52 / 24$ & 0,065 \\
\hline PKG Time (h) & $5,3 \pm 1,9$ & $9,2 \pm 2,0$ & $\mathbf{0 , 0 0 1 *}$ \\
\hline
\end{tabular}

Değerler ortalama \pm SD veya sayı (\%)șeklinde verildi. Ant. MI: Anterior Miyokart Enfarktüs KAH: Koroner Arter Hastalı̆̆ı, DM: Diyabetes Mellitus, HT: Hipertansiyon, HL: Hiperlipidemi, SKB: Sistolik kan basincı, DKB: Diastolik kan basinc1, NB: Nabiz basinc1,

PKG: Perkutan Koroner Girisim, n: olgu sayısı. ${ }^{*}=\mathrm{p}<0,05$ İstatistiksel olarak anlamlı kabul edilmistit.

Çalışmaya alınan ve ST rezolüsyonu olan hastaların yaşları 34 ile 90 yıl arasında ve ortalaması 57,9 yıl; ST rezolüsyonu olmayan grubun yaşları 34 ile 92 yıl arasında ve ortalaması 66,5 y1l olarak saptandı. ST rezolüsyonu olan gruptaki kişilerin 73 'ü $(\% 59,8)$ erkek, 49’u $(\% 40,2)$ kadındı. ST rezolüsyonu olmayan gruptaki kişilerin ise 64'ü $(\% 48,9)$ erkek, 67'si $(\% 51,1)$ kadındı. Cinsiyet açısından iki grup benzerdi. Yaş açısından ise ileri yaşın ST rezolüsyonu üzerine olumsuz etkisi saptand $1(p=0,001)$.

ST rezolüsyonu olan hastaların 71'i $(\% 58,1)$ Anterior MI, 51 'i $(\% 41,9)$ Non-Anterior MI idi. ST rezolüsyonu olmayan hastaların ise 55'i (\%42) Anterior MI iken, 76's1 (\%48) Non- 
Anterior MI di. ST rezolüsyonu olan hastaların 70'ine $(\% 57,4)$ LAD PCI, 33'üne (\%27) RCA PCI, 19'una (\%15,6) Cx PCI yapıldı. ST rezolüsyonu olmayan hastaların $55^{\prime}$ ine (\%42) LAD PCI, 52'sine (\%39,7) RCA PCI, 24'üne (\%18,3) Cx PCI yapıldı. ST rezolüsyonu olan hastaların göğüs ağrısı başlangıcından PKG yapılan zamana kadar geçen ortalama süreleri 5,3 $\pm 1,9$ saat iken; ST rezolüsyonu olmayan hastaların ortalama $\mathrm{PKG}$ süreleri 9,2 $\pm 2,0$ saat olarak tespit edildi. Anterior MI ile gelen hastalarda ST rezolüsyonu açısından sınırda anlamlılık tespit edildi ( $p=0,043)$. Yapılan işlem açısından iki grup arasında anlamlı fark bulunmaz iken ( $\mathrm{p}=0,065)$; PKG süresi uzadıkça ST rezolüsyonunun olumsuz olarak etkilendiği tespit edildi $(\mathrm{p}=0,001)$.

Risk faktörleri açısından kıyaslandığında ST rezolüsyonu olan grupta bilinen KAH'1 olan $12(\% 9,8)$ hasta var iken; ST rezolüsyonu olmayan grupta $81(\% 61,8)$ hastanın daha önceden KAH öyküsü olduğu tespit edildi. ST rezolüsyonu olan grupta bilinen DM'u olan $25(\% 20,5)$ hasta var iken; ST rezolüsyonu olmayan grupta $58(\% 44,3)$ hastanın DM ile takipli olduğu tespit edildi. ST rezolüsyonu olan grupta bilinen HT'u olan $18(\% 14,8)$ hasta var iken; ST rezolüsyonu olmayan grupta 110 (\%84) hastanın HT ile takipli olduğu tespit edildi. ST rezolüsyonu olan grupta bilinen HL'si olan $17(\% 13,9)$ hasta var iken; ST rezolüsyonu olmayan grupta $53(\% 40,5)$ hastanın HL ile takipli olduğu tespit edildi. ST rezolüsyonu olan grupta hereditesi olan $22(\% 18)$ hasta var iken; ST rezolüsyonu olmayan grupta $10(\% 7,6)$ hastanın hereditesinin olduğu tespit edildi. ST rezolüsyonu olan grupta $48(\% 39,3)$ hastanın sigara kullanım öyküsü var iken; ST rezolüsyonu olmayan grupta 56 $(\% 42,7)$ hastanın sigara kullanım öyküsü olduğu tespit edildi. ST rezolüsyonu olan grupta $16(\% 13,1)$ hastanın obezitesi var iken; ST rezolüsyonu olmayan grupta $28(\% 21,4)$ hastanın obezite ile takipli olduğu tespit edildi.

İki grup KAH ( $\mathrm{p}=0,001), \mathrm{DM}(\mathrm{p}=0,001), \mathrm{HT}(\mathrm{p}=0,001), \mathrm{HL}$ $(\mathrm{p}=0,001)$ açısından kıyaslandığında istatistiksel olarak anlamlı bulundu, ST rezolüsyonunun bundan olumsuz etkilendiği saptand1. Sigara $(p=0,582)$, Obezite $(p=0,08)$, ve Heredite $(p=0,134)$ açısından kıyaslandığında ise gruplar arası anlamlı fark bulunmadi.

ST rezolüsyonu olan ve olmayan gruplar NB açısından kıyaslandığında; ST rezolüsyonu olan grubun ortalama SKB / DKB değeri 119,3 $\pm 13,5$ olarak saptanırken, ST rezolüsyonu

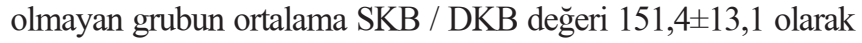
saptand1. ST rezolüsyonu olan grubun NB değeri $41,0 \pm 7,1$ olarak tespit edilirken, ST rezolüsyonu olmayan grubun NB değeri $62,9 \pm 6,7$ olarak tespit edildi. İki grup istatistiksel olarak kıyaslandığında NB değeri arttıkça ST segment rezolüsyonunun bundan olumsuz etkilendiği saptandı $(\mathrm{p}=0,001)$.

\section{Labarotuvar Verilerinin Karșılaștırılması}

Çalışmaya alınan hastaların biyokimya ve tam kan verilerinin karşılaştırılması Tablo 2'de gösterilmiştir.

ST rezolüsyonu olan hasta grubu ile ST rezolüsyonu olmayan hasta grubu tam kan verileri açısından karşılaştırıldığında istatistiksel olarak anlamlı fark tespit edilmedi. İki grup biyokimyasal veriler açısından karşılaştırıldığında ise Kre, HDL-kolesterol ve $\mathrm{Na}$ değerleri arasında istatistiki olarak
Tablo 2. ST rezolusyonu olan ve olmayan hastaların biyokimya ve tam kan verilerinin karşılaştırılması

\begin{tabular}{lccc}
\hline & $\begin{array}{c}\text { ST Rez. } \\
\text { Var } \\
\text { (n:122) }\end{array}$ & $\begin{array}{c}\text { ST Rez. } \\
\text { Yok } \\
\text { (n:131) }\end{array}$ & P Değeri \\
\hline Glukoz (mg/dl) & $116,6 \pm 51,1$ & $163,5 \pm 93,5$ & $\mathbf{0 , 0 1 3 *}$ \\
\hline Kreatinin (mg/dl) & $1,0 \pm 0,2$ & $1,0 \pm 0,2$ & 0,073 \\
\hline $\begin{array}{l}\text { LDL-Kolesterol } \\
\text { (mg/dl) }\end{array}$ & $123,3 \pm 13,2$ & $134,5 \pm 17,8$ & $\mathbf{0 , 0 0 1 *}$ \\
\hline $\begin{array}{l}\text { HDL-Kolesterol } \\
\text { (mg/dl) }\end{array}$ & $42,4 \pm 5,9$ & $42,2 \pm 4,4$ & 0,709 \\
\hline AST (mg/dl) & $80,8 \pm 10,4$ & $93,7 \pm 16,5$ & $\mathbf{0 , 0 1 7 ^ { * }}$ \\
\hline ALT (mg/dl) & $43,1 \pm 6,9$ & $38,5 \pm 11,8$ & $\mathbf{0 , 0 1 4 *}$ \\
\hline Na (mmol/L) & $138,5 \pm 2,7$ & $140,9 \pm 4,1$ & 0,062 \\
\hline K (mmol/L) & $3,8 \pm 0,2$ & $4,2 \pm 0,4$ & $\mathbf{0 , 0 3 8 ^ { * }}$ \\
\hline LDH (U/L) & $335,2 \pm 62,3$ & $377,9 \pm 60,3$ & $\mathbf{0 , 0 0 1 *}$ \\
\hline Pik CK-MB (U/L) & $103,1 \pm 15,5$ & $121,2 \pm 22,4$ & $\mathbf{0 , 0 0 1 *}$ \\
\hline Hemoglobin (g/dl) & $12,7 \pm 1,1$ & $11,8 \pm 1,5$ & 0,349 \\
\hline PLT (×10 $)$ & $308,7 \pm 31,3$ & $301,1 \pm 29,6$ & 0,351 \\
\hline
\end{tabular}

Değerler ortalama \pm SD șeklinde verildi., LDL: Düşük dansiteli lipoprotein, HDL: Yüksek dansiteli lipoprotein, AST: Aspartat aminotransferaz, ALT: Alanin aminotransferaz Na: Sodyum, K: Potasyum, LDH: Laktat Dehidrogenaz, PLT: Trombosit, n: olgu sayısı. ${ }^{*}=\mathrm{p}<0,05$ İ Istatistiksel olarak anlamlı kabul edilmiștir.

Tablo 3. ST rezolüsyonu olan ve olmayan hastaların ekokardiyografik verilerinin karşılaştırılması

\begin{tabular}{lccc}
\hline & $\begin{array}{c}\text { ST Rez. } \\
\text { Var } \\
\text { (n:122) }\end{array}$ & $\begin{array}{c}\text { ST Rez. } \\
\text { Yok } \\
\text { (n:131) }\end{array}$ & P Değeri \\
\hline EF (\%) & $46,1 \pm 7,8$ & $38,6 \pm 11,9$ & $\mathbf{0 , 0 0 1 *}$ \\
\hline SVDSÇ (cm) & $4,3 \pm 0,3$ & $5,0 \pm 0,3$ & $\mathbf{0 , 0 2 4 ^ { * }}$ \\
\hline SVSSÇ (cm) & $2,5 \pm 0,2$ & $2,6 \pm 0,1$ & $\mathbf{0 , 0 3 7 ^ { * }}$ \\
\hline AoS (cm) & $3,0 \pm 0,1$ & $3,0 \pm 0,1$ & 0,152 \\
\hline AoD (cm) & $2,7 \pm 0,2$ & $2,8 \pm 0,1$ & $\mathbf{0 , 0 2 1 *}$ \\
\hline ÇD (cm) & $0,3 \pm 0,07$ & $0,2 \pm 0,04$ & $\mathbf{0 , 0 0 1 *}$ \\
\hline LA (cm) & $3,6 \pm 0,2$ & $4,0 \pm 0,3$ & 0,061 \\
\hline IVS (cm) & $1,0 \pm 0,09$ & $1,2 \pm 0,14$ & $\mathbf{0 , 0 3 7 ^ { * }}$ \\
\hline PW (cm) & $0,8 \pm 0,06$ & $0,9 \pm 0,09$ & 0,713 \\
\hline SPAB (mmHg) & $27,3 \pm 7,6$ & $35,7 \pm 11,3$ & $\mathbf{0 , 0 4 4 *}$ \\
\hline
\end{tabular}

Değerler ortalama \pm SD şeklinde verildi. EF: Ejeksiyon fraksiyonu SVSSÇ: LV Sistol sonu çap, SVDSÇ: LV Diyastol sonu çap, AoS: Aort sistolik Çapı, AoD: Aort Diyastolik Çapı SPAB: Sistolik pulmoner arter basıncı, ÇD: Çap Değişimi, LA: Sol atriyum, IVS: Interventriküler Septum

PW: posterior duvar, n: olgu sayısı. ${ }^{*}=0<0,05$ İstatistiksel olarak anlamlı kabul edilmiştir.

anlamlı fark bulunmaz iken, glukoz, LDL-kolesterol, AST, ALT, K, LDH değerleri arasında istatistiki olarak anlamlı fark tespit edildi.

\section{Konvansiyonel Ekokardiyografik Verilerin Karşılaştırılması}

Çalışmada ST rezolüsyonu olan ve ST rezolüsyonu olmayan grupların konvansiyonel ekokardiyografik ölçümleri Tablo 3 'te verilmiştir.

Her iki grup ekokardiyografik olarak değerlendirildiğinde ST

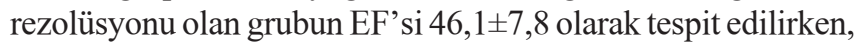
ST rezolüsyonu olmayan grubun EF'si 38,6 $\pm 11,9$ olarak tespit edildi. Bu fark istatistiksel olarak da anlamlı bulundu $(\mathrm{p}=0,001)$ Sol ventrikül çapları irdelendiğinde ST rezolusyonu olan 
grubunun LV sistolik çapı $(\mathrm{p}=0,037)$, LV diyastolik çap1 $(\mathrm{p}=0,024)$ ve septum kalınlığı $(\mathrm{p}=0,037)$ ST rezolüsyonu olmayan gruba göre anlamlı olarak daha düşüktü. Her iki grubun aortik çapları kıyaslandığında AoD çap $(p=0,021)$ ve diyastolik çap ile sistolik çap farkını gösteren çap değişimi ( $\mathrm{p}=0,001)$ ST rezolüsyonu olan grupta daha düşük tespit edildi ve bu fark istatistiksel olarak anlamlı bulundu. İki grubun SPAB'ları karşılaştırıldığında ST rezolüsyonu olan grupta $27,3 \pm 7,6 \mathrm{mmHg}$, ST rezolüsyonu olmayan grupta ise $35,7 \pm 11,3 \mathrm{mmHg}$ olarak ölçüldü. Bu fark istatistiksel olarak da anlamlı bulundu $(\mathrm{p}=0,044)$.

Her iki grup LA çapı $(p=0,061)$, sistolik aortik çap $(p=0,152)$ ve posterior duvar kalınlığı $(\mathrm{p}=0,713)$ açısından benzerdi.

\section{Aortik Sertlik Parametrelerinin Karşılaştırılması}

Çalışmada ST rezolüsyonu olan ve ST rezolüsyonu olmayan grupların aortik sertlik parametreleri karşılaştırılması Tablo 4'te verilmiştir.

Tablo 4. ST rezolüsyonu olan ve olmayan hastaların aortik sertlik parametrelerinin karşılaştırılması

\begin{tabular}{lccc}
\hline & $\begin{array}{c}\text { ST Rez. } \\
\text { Var } \\
(\mathbf{n : 1 2 2})\end{array}$ & $\begin{array}{c}\text { ST Rez. } \\
\text { Yok } \\
(\mathbf{n : 1 3 1 )}\end{array}$ & P Değeri \\
\hline Aortik strain (\%) & $14,5 \pm 3,7$ & $7,8 \pm 1,8$ & $\mathbf{0 , 0 0 0 1 *}$ \\
\hline $\begin{array}{l}\text { Aortik Distensibilite } \\
\left(\mathbf{c m}^{2} / \text { dyn/10 }\right.\end{array}$ & $7,4 \pm 3,0$ & $2,5 \pm 0,8$ & $\mathbf{0 , 0 0 0 1 *}$ \\
\hline $\begin{array}{l}\text { Aortik Sertlik } \\
\text { İn-deksi }\end{array}$ & $3,1 \pm 0,9$ & $7,2 \pm 2,4$ & $\mathbf{0 , 0 0 0 1 *}$ \\
\hline $\begin{array}{l}\text { Aortik Elastik } \\
\text { Modü-lüs (E(p)) }\end{array}$ & $303 \pm 105$ & $863 \pm 321$ & $\mathbf{0 , 0 0 0 1 *}$ \\
\hline
\end{tabular}

Değerler ortalama \pm SD şeklinde verildi. $n$ : olgu sayısı. ${ }^{*}=\mathrm{p}<0,05$ istatistiksel olarak anlamlı kabu edilmiştir.

Çalışmamızda her iki grup aortik sertlik parametreleri açısından değerlendirildiğinde; ST rezolüsyonu olan grupta aortik strain değeri 14,5 $\pm 3,7$ bulunurken, ST rezolüsyonu olmayan grupta $7,8 \pm 1,8$ olarak tespit edildi. ST rezolüsyonu olan grupta aortik distensibilite değeri $7,4 \pm 3,0$ bulunurken, ST rezolüsyonu olmayan grupta 2,5 $\pm 0,8$ olarak tespit edildi. Aortik strain ve Aortik distenbilite ST rezolüsyonu olan grupta belirgin olarak daha yüksek saptandı ve bu durum istatistiksel açıdan da oldukça anlamlıydı (sırasıyla p=0,0001, $\mathrm{p}=0,0001$ ).

ST rezolüsyonu olan grupta aortik sertlik indeksi değeri $3,1 \pm 0,9$ bulunurken, ST rezolüsyonu olmayan grupta 7,2 $\pm 2,4$ olarak tespit edildi. ST rezolüsyonu olan grupta aortik elastik modülüs değeri $303 \pm 105$ bulunurken, ST rezolüsyonu olmayan grupta $863 \pm 321$ olarak tespit edildi. Aortik sertlik indeksi ve aortik elastik modülüs ST rezolüsyonu olan grupta belirgin olarak daha düşük saptandı ve bu durum istatistiksel açıdan da oldukça anlamlıydı (sırasıyla p=0,0001, $\mathrm{p}=0,0001$ ).

\section{Aortik Sertlik Parametreleri ve ST Segment Rezolüsyonu Arasındaki Korelasyon analizi}

Çalışmamızdaki aortik sertlik parametreleri ve ST regment Rezolüsyonu arasındaki korelasyon analizi Tablo 5'te verilmiştir.

Aortik sertlik parametreleri ile ST segment rezolüsyonu arasındaki korelasyon incelendiğinde; Aortik strain $(\mathrm{r}=0,516$,
Tablo 5. Aortik sertlik parametreleri ve ST regment rezolüsyonu korelasyonu

\begin{tabular}{lcc}
\hline & r değeri & p değeri \\
\hline Aortik strain & 0,516 & $\mathbf{0 , 0 0 1 *}$ \\
\hline Aortik Distensibilite & 0,258 & $\mathbf{0 , 0 2 6}{ }^{*}$ \\
\hline Aortik Sertlik İndeksi & $-0,180$ & $\mathbf{0 , 0 4 8} *$ \\
\hline Aortik Elastik Modülüs & $-0,449$ & $\mathbf{0 , 0 0 2} *$ \\
\hline r: Korelasyon katsayısı. ${ }^{*}=0,05$ istatistiksel olarak anlamlı kabul edilmiştir. &
\end{tabular}

$\mathrm{p}=0,001)$ ve aortik distensibilite $(\mathrm{r}=0,258, \mathrm{p}=0,026)$ ile ST rezolüsyonu olması arasında anlamlı düzeyde pozitif korelasyon saptanırken, aortik sertlik indeksi $(\mathrm{r}=-0,180$, $\mathrm{p}=0,048)$ ve aortik elastik modülüs $(\mathrm{r}=-0,449, \mathrm{p}=0,002)$ değerleri ile ST rezolüsyonu olması arasında anlamlı düzeyde negatif korelasyon olduğu görüldü.

\section{ST Segment Rezolüsyonu ile Diğer Parametreler Arasındaki Korelasyon}

Çalışmada bivariate korelasyon analizinde ST segment rezolüsyonu ile anlamlı ilişki gösteren parametreler Tablo 6' da verilmiştir.

Tablo 6. ST segment rezolüsyonu ile diğer parametreler arasındaki korelasyon

\begin{tabular}{lcc}
\hline & r değeri & p değeri \\
\hline Yaş & $-0,468$ & $0,001^{*}$ \\
\hline KAH & -0.384 & $0,014^{*}$ \\
\hline HT & $-0,246$ & $0,029^{*}$ \\
\hline PKG Time & $-0,483$ & $0,001^{*}$ \\
\hline Pik CK-MB & $-0,252$ & $0,027^{*}$ \\
\hline EF & 0,216 & $0,031^{*}$ \\
\hline NB & $-0,312$ & $0,019^{*}$ \\
\hline ÇD & 0,205 & $0,038^{*}$ \\
\hline KAH: Koroner Arter Hastalğ̆, HT: Hipertansiyon, PKG: Perkutan Koroner Girisim, EF: Ejeksüyon
\end{tabular}

KAH: Koroner Arter Hastalığı, HT: Hipertansiyon, PKG: Perkutan Koroner Girişim, EF: Ejeksüyon Fraksiyonu, NB: Nabız Basıncı, ÇD: Çap Değişimi, r: Korelasyon katsayısı, ${ }^{*}=\mathrm{p}<0,05$ istatistiksel olarak anlamlı kabul edilmiștir.

ST segment rezolüsyonu olmas1 ile $\mathrm{EF}(\mathrm{r}=0,216, \mathrm{p}=0,031)$ ve aortik sistolik-diyastolik çap değişimi $(\mathrm{r}=0,205, \mathrm{p}=0,038)$ arasında anlamlı düzeyde pozitif korelasyon saptanırken, ST segment rezolüsyonu olması ile yaş $(\mathrm{r}=-0,468, \mathrm{p}=0,001), \mathrm{KAH}$ $(\mathrm{r}=-0,384, \mathrm{p}=0,014)$, HT $(\mathrm{r}=-0,246, \mathrm{p}=0,029)$, PKG Time $(\mathrm{r}=$ $-0,483, \mathrm{p}=0,001)$, pik CK-MB $(\mathrm{r}=-0,252, \mathrm{p}=0,027)$ ve nabiz basincı( $r=-0,312, p=0,019)$ arasinda anlamlı düzeyde negatif korelasyon saptand.

\section{Tartışma}

Bu çalışmamızda PKG sonrası STEMİ hastalarında başarılı elektrokardiyografik reperfüzyon ve aortik sertlik ilişkisi araştırılmış ve başarılı elektrokardiyografik reperfüzyon saptanan hastalarda aortik sertlik parametrelerinin daha iyi, enfarkt genişliğinin ise daha küçük olduğu saptanmıştır.

Aortik sertlik ateroskleroz ile iç içe girmiş ve başta yaş olmak üzere kardiyovasküler risk faktörlerinden etkilenen kronik bir durumdur. Aortik sertliğin gelişecek kardiyovasküler olayları 
öngördürücü değeri olması bu iki klinik durumun benzer patofizyolojiye sahip olduğunu düşündürür. Aortik sertlik sağlıklı bireylerde koroner arter hastalığı ve inme gelişimi için bağımsız bir prediktör olduğu gibi genel popülasyonda da mortalitenin önemli bir prediktörü olduğu çeşitli çalışmalarda ortaya konmuştur (12).

Yeniden yapılanma miyokart enfarktüsünden hemen sonra başlayan ve uzun dönemde kronik kalp yetersizliğine kadar giden bir süreçtir (13). Sol ventrikülün uzun süre volüm ve basınç yükü altında çalışması, Mİ'ye bağlı miyokart dokusunun kaybının fazlalığı bu süreci hızlandırıcı etki yapar. Mikrovasküler dolaşımın hasarlanması bu süreçte bilinen temel etkenlerden biridir. Epikardiyal kan akımın sağlanması hücresel düzeyde dolaşımın sağlandığını göstermez ve bu durum yeniden yapılanma için önem arz eder. ST segment rezolüsyonu yakın ve uzun dönem sol ventrikül fonksiyonları üzerine önemli bir göstergedir ve mikrovasküler dolaşımın sağlandığı konusunda bilgi verir (14-15).

Miyokart enfarktüsü sonrasında aortik sertliğin mortalite artışına sebep olup olmadığı konusunda henüz yeterli veri bulunmasa da, aortik sertliğin aortik kompliyansı düşürmesi yoluyla miyokart enfarktüsü sonrası yeniden yapılanma gelişimine neden olabileceği düşünülmektedir. Aortik sertlik artışı aortanın sistoldeki rezervuar özelliğini bozar. Bu durum merkezi bir kan basıncı artışı ile sonuçlanır. Bu da sol ventrikülün önündeki iş yükünü artırarak iskemiye ve yeniden yapılanmaya yatkın bir ortam hazırlayacaktır. Miyokart enfarktüsü sonrasında aortik sertliğin değerlendirildiği bir çalışmada, yaş ile artan aortik sertliğin benzer enfarkt alanlarına rağmen yeniden yapılanmaya neden olabileceği gösterilmiştir (16). $\mathrm{Bu}$ çalışmada yeniden yapılanma gelişiminde aortik sertliğin neden olduğu art yük artışı öne sürülmüş fakat hasta grupları aortik sertlik ile reperfüzyon başarısı ilişkisi açısından değerlendirilmemişti. Çalışmada, manyetik rezonans ile saptanan benzer enfarkt alanlarına rağmen, yaşlilarda gençlere göre EF'nin daha düşük olduğu ve sistol sonu volümlerinin daha fazla olduğu gösterilmiş ve bu etkinin aortik distensibilitede ki azalmanın art yükü artırmasının bir sonucu olabileceğini ileri sürmüşlerdir. Bununla birlikte reperfüzyon çağı öncesi yapılan çalışmalarda, yaşlılarda $\beta$-adrenerjik yanıtsızlık, gecikmiș erken diyastolik dolum, endotelyal disfonksiyon, sol ventrikülün artmış siferik yapısı ve ön yüke artmış bağımlılık durumlarının olması yeniden yapılanmanın olası nedenleri arasında gösterilmiş ve yaşlılardaki Mİnin daha kötü prognozlu olmasında rol oynayabilecekleri düşünülmüştür. Reperfüzyon çağından sonra ise koroner damar açıklığının sağlanması ve miyokart enfarktüsü sonrası optimal medikal tedavinin gün geçtikçe daha yaygın kullanılması ventriküler yeniden yapılanma ile mücadeleyi güçlendirmiştir. Reperfüzyonun sağlanması miyokardiyal doku kaybını azaltarak yeniden yapılanmanın tetiklenmesini azaltacaktır (17).

Çalışmamızda da aortik strain ve distensibilitesi kötü olan hastalarda enfarkt alanının daha geniş olduğunu düşündüren daha yüksek pik CK-MB değerleri elde edilmiştir. Ejeksiyon fraksiyonunun da aortik strain yüksekliğiyle korele olduğu gösterilmiştir. Perkütan koroner girişim sonrası anlamlı ST rezolüsyonu görülen hastalarda aortik sertliğin(aortik strain ve distensibilite), pik CK-MB değerinin ve SVEF'sinin anlamlı olarak daha iyi olduğu görülmüştür. $\mathrm{Bu}$ durum elektrokardiyografik reperfüzyonun, akut dönemde miyokardiyal yeniden yapılanma üzerinde belirleyici olduğunu ve aortik sertlik ile korele olduğunu göstermektedir. ST rezolüsyonu olan hasta grubunda aortik sertliğin dolayısıyla endotel fonksiyonlarının daha iyi olmasına bağlı olarak mikrovasküler dolaşımın daha hızlı düzelmesi mevcut bulguları açıklayabilir. Aortik stiffness yaşlanmadan sistemik hastalıklara kadar çok çeşitli durumdan etkilenmektedir. Yaş hariç diğer özellikler açısından fark olmayan gruplarda yaşlanma ile aortik sertlik artışının meydana geldiği gösterilmiştir.Yaşlanma sürecinde arter duvarında bulunan elastin ve kollajen fibrillerdeki yapısal değişim bu sertlik artışından sorumlu olabilir (18). Bizim çalışmamızda da artan yaşla birlikte aortik sertliğinde ilerlediği ve ST rezolüsyonunun bundan olumsuz etkilendiği gösterilmiştir.

Anjiografik olarak normal aortası olan, koroner arter hastalıklı normotansif hastaların aortik distensibilitesi, aynı yaş grubundaki normal sol ventrikül fonksiyonlu ve koroner arterli göğüs ağrılı hastalarla karşılaştırıldığında daha düşük bulunmuştur (7). Cameron ve arkadaşları tarafından aortik elastik özellikleri gösteren noninvaziv tekniklerin kardiyovasküler risk ile ilgili bilgiler verilebileceği, fakat koroner kalp hastalığ için kesin diyagnostik test olmadığ1 bildirilmiştir (19). Stefanadis ve arkadaşlarının yaptığı çalışmada invaziv ve noninvaziv yöntemlerle basınç çap ilişkileri ile aort elastisitesi değerlendirilmiş, ve koroner arter hastalığı olan hastalarda tekrarlayan koroner olaylarda aortik elastisitenin kuvvetli ve bağımsız bir risk faktörü olduğu gösterilmiştir (20). Bizim çalışmamızda da KAH ile aortik stiffness arasında anlamlı korelasyon olduğu saptandı ve elektrokardiyografik reperfüzyonun bundan olumsuz etkilendiği gösterildi.

Mevcut çalışmamız bir ön çalışma niteliğindedir. Çalışma sonuçları, aortik sertliğin reperfüzyon başarısını predikte edebileceğini ve Mİ sonrası sol ventriküler sistolik fonksiyonları ve enfarkt alanı ile ilişkili olduğunu düşündürtmektedir. Özellikle aortik sertliğin miyokart enfarktüsü sonrası prognozdaki etkisi ve aortik sertliği geriye döndürebilecek farmakolojik ve farmakolojik olmayan yaklaşımların önemi büyük çaplı randomize çalışmalar gerektiren konulardır.

Çalışmamızda enfarkt alanının genişliğinin pik CK-MB ile değerlendirilmesi nükleer tıp ve manyetik rezonans gibi radyolojik yöntemlere göre önemli kısıtlılık getirmektedir. Yinede pik CK-MB düzeyi birçok çalışmada kendine yer bulmuş iyi tanımlanmış bir metottur (21). Çalışmamızın diğer kısıtlılıkları da aortik sertlik ölçümlerinin ekokardiyografik yöntemler ile elde edilmesi ve ST segment rezolüsyon ölçümleridir. Her ne kadar ekokardiyografik ölçümler çalışmalarda direkt ölçümlere yakın sonuçlar verse de (20) çalışmanın direkt ölçüm metotları ile yapılması ve ST segment rezolüsyonu yerine miyokardiyal kontrast ekokardiyografinin mikrovasküler dolaşımın değerlendirilmesinde kullanılması çalışmaya daha objektif veri sağlayabilirdi (22). 
Çalışmamızda her ne kadar erken dönem yeniden yapılanma saptanmaya çalışılmışsa da, miyokart enfarktüsü sonrası canlı olmasına rağmen fonksiyonel olmayan hücrelerin tekrar kontraktil özellik kazanması mümkün olabilir. Bu nedenle çalışmamızda SVEF'nin erken dönemde değerlendirilmesi, geç dönemde oluşabilecek muhtemel düzelme(ters yeniden yapılanma) veya yeniden yapılanmaya bağl1 kötüleşmenin gözden kaçırılmasına sebep olabilen diğer bir kısıtlılıktır.

\section{Sonuç}

Çalışmamızda, PKG uygulanan STEMİ hastalarında artmış aortik sertliğin, daha kötü elektrokardiyografik reperfüzyon ile ilișkili olduğunu ve daha büyük enfarkt alanlarına neden olabildiğini tespit ettik. Bu durum, aortik sertliğin enfarktüs sonrası yeniden yapılanmaya reperfüzyon üzerinden de katk1sı olabileceğini düşündürmektedir. Çalışmanın daha objektif görüntüleme yöntemleri ile daha büyük bir popülasyonda yapılması aortik sertliği, revaskülarize edilen STEMI hastalarında iskemik kardiyomiyopati gelişimi açısından ek bir risk faktörü olarak tanımlamaya yardımcı olabileceğini düşünmekteyiz.

Bu çalışma 5-8 Ekim 2017 tarihinde Antalya Titanic de luxe hotelde düzenlenen 33. Uluslararası katılımlı Türk Kardiyoloji Kongresi'nde sözlü sunum olarak sunulmuştur.

\section{Kaynaklar}

1. Braunwald E, Antman EM, Beasley JW, Califf RM, Cheitlin MD, Hochman JS, et al. ACC/AHA guidelines for the management of patients with unstable angina and non-STsegment elevation myocardial infarction: executive summary and recommendations. Circulation. 2000; 102(10): 1193-209.

2. Fuster V, Badimon L, Badimon JJ, Chesebro JH. The pathogenesis of coronary artery disease and the acute coronary syndromes. New England Journal of Medicine. 1992; 326(4): 242-50.

3. Anderson JL, Adams CD, Antman EM, Bridges CR, Califf RM, Casey DE, et al. ACC/AHA 2007 guidelines for the management of patients with unstable angina/non-STelevation myocardial infarction: a report of the American College of Cardiology/American Heart Association Task Force on Practice Guidelines (Writing Committee to Revise the 2002 Guidelines for the Management of Patients With Unstable Angina/Non-ST-Elevation Myocardial Infarction) developed in collaboration with the American College of Emergency Physicians, the Society for Cardiovascular Angiography and Interventions, and the Society of Thoracic Surgeons endorsed by the American Association of Cardiovascular and Pulmonary Rehabilitation and the Society for Academic Emergency Medicine. Journal of the American College of Cardiology. 2007; 50(7): e1-e157.

4. Orlova IA, Nuraliev EY, Yarovaya EB, Ageev FT. Prognostic value of changes in arterial stiffness in men with coronary artery disease. Vascular health and risk management. 2010; 6: 1015.

5. Lee RT, Kamm RD. Vascular mechanics for the cardiologist. Journal of the American College of Cardiology. 1994; 23(6):
1289-95.

6. Laurent S, Boutouyrie P, Asmar R, Gautier I, Laloux B, Guize L, et al. Aortic stiffness is an independent predictor of all-cause and cardiovascular mortality in hypertensive patients. Hypertension. 2001; 37(5): 1236-41.

7. Stefanadis C, Wooley CF, Bush CA, Kolibash AJ, Boudoulas H. Aortic distensibility abnormalities in coronary artery disease. The American journal of cardiology. 1987; 59(15): 1300-4.

8. Vlachopoulos C, Aznaouridis K, Stefanadis C. Prediction of cardiovascular events and all-cause mortality with arterial stiffness: a systematic review and meta-analysis. Journal of the American College of Cardiology. 2010; 55(13): 1318-27.

9. Stefanadis C, Dernellis J, Tsiamis E, Stratos C, Diamantopoulos L, Michaelides A, et al. Aortic stiffness as a risk factor for recurrent acute coronary events in patients with ischaemic heart disease. European Heart Journal. 2000; 21(5): 390-6.

10. Mitchell GF, Moyé LA, Braunwald E, Rouleau J-L, Bernstein V, Geltman EM, et al. Sphygmomanometrically determined pulse pressure is a powerful independent predictor of recurrent events after myocardial infarction in patients with impaired left ventricular function. Circulation. 1997; 96(12): 4254-60.

11. Vaccarino V, Berger AK, Abramson J, Black HR, Setaro JF, Davey JA, et al. Pulse pressure and risk of cardiovascular events in the systolic hypertension in the elderly program. The American journal of cardiology. 2001; 88(9): 980-6.

12. Mattace-Raso FU, van der Cammen TJ, Hofman A, van Popele NM, Bos ML, Schalekamp MA, et al. Arterial stiffness and risk of coronary heart disease and stroke. Circulation. 2006; 113(5): 657-63.

13. Pfeffer M, Ph. D, Marc A. Left ventricular remodeling after acute myocardial infarction. Annual review of medicine. 1995; 46(1): 455-66.

14. Tomaszuk-Kazberuk A, Korecki J, Kochman W, Dobrzycki S, Musiał W. Rapid resolution of ST segment elevation predicts recovery of left myocardial contraction in patients with acute myocardial infarction treated with percutaneous coronary angioplasty. Przeglad lekarski. 2001; 59(8): 638-41.

15. Araszkiewicz A, Lesiak M, Grajek S, Mularek-Kubzdela T, Popiel M, Cieśliński A. Value of ST-segment elevation resolution after primary coronary angioplasty in predicting early and late left ventricular function in patients with anterior acute myocardial infarction. Polski merkuriusz lekarski: organ Polskiego Towarzystwa Lekarskiego. 2005; 19(109): 16-9.

16. Hirsch GA, Ingkanisorn WP, Schulman SP, Gerstenblith G, Dyke CK, Rhoads KL, et al. Age-Related Vascular Stiffness and Left Ventricular Size After Myocardial Infarction. The American journal of geriatric cardiology. 2007; 16(4): 222-8.

17. Fleg JL, O'connor F, Gerstenblith G, Becker L, Clulow J, Schulman S, et al. Impact of age on the cardiovascular response to dynamic upright exercise in healthy men and women. Journal of Applied Physiology. 1995; 78(3): 890-900. 
18. Mitchell GF, Parise H, Benjamin EJ, Larson MG, Keyes MJ, Vita JA, et al. Changes in arterial stiffness and wave reflection with advancing age in healthy men and women. Hypertension. 2004; 43(6): 1239-45.

19. Cameron JD, Jennings GL, Dart AM. Systemic arterial compliance is decreased in newly-diagnosed patients with coronary heart disease: implications for prediction of risk. Journal of cardiovascular risk. 1996; 3(6): 495-500.

20. Stefanadis C, Stratos C, Boudoulas H, Kourouklis C, Toutouzas P. Distensibility of the ascending aorta: comparison of invasive and non-invasive techniques in healthy men and in men with coronary artery disease. European Heart Journal.
1990; 11(11): 990-6.

21. Hedström E, Åström-Olsson K, Öhlin H, Frogner F, Carlsson M, Billgren T, et al. Peak CKMB and cTnT accurately estimates myocardial infarct size after reperfusion. Scandinavian Cardiovascular Journal. 2007; 41(1): 44-50.

22. Galiuto L, Garramone $B$, Scarà A, Rebuzzi AG, Crea F, La Torre G, et al. The extent of microvascular damage during myocardial contrast echocardiography is superior to other known indexes of post-infarct reperfusion in predicting left ventricular remodeling: results of the multicenter AMICI study. Journal of the American College of Cardiology. 2008; 51(5): 552-9. 